\title{
Social Media as a Communication Tool to Support University Student - Services: Affordances, Limitations and Opportunities for Innovations
}

\author{
Charity Tecson-Turano \\ Department of Communications, Linguistics and Literature University of San Carlos, Cebu City, Philippines \\ Email address: \\ chatecson@gmail.com \\ To cite this article: \\ Charity Tecson-Turano. Social Media as a Communication Tool to Support University Student - Services: Affordances, Limitations and \\ Opportunities for Innovations. International Journal of Information and Communication Sciences. Vol. 2, No. 5, 2017 pp. 75-85. \\ doi: $10.11648 /$ j.ijics.20170205.14
}

Received: June 19, 2017 Accepted: July 3, 2017 Published: October 24, 2017

\begin{abstract}
This study titled Social Media as a Communication Tool to Support University Student-Services: Affordances, Limitations and Opportunities for Innovations sought to determine the affordances of social media as a communication tool to support student services as perceived by the administrators, faculty, and students; the identified limitations and glitches of social media as a communication tool to support student services as experienced by the respondents and ways to address these limitations and glitches; and the opportunities to enhance usage of social media for university student services. Department academic chairs, faculty coordinators and faculty members ( 8 respondents), and students (123 respondents) from seven academic departments participated in the study. A qualitative approach through open-ended survey was employed. The Theory of Affordances by James J. Gibson served as the theoretical underpinning of the study. The respondents declared that the use of social media has significantly aided them in their enrollment concerns, academic department-student collaboration and academic department-student communications in general. Opportunities for continuous interactions to discuss student concerns that should be attended to by their respective academic departments were found to be favorable. Blocking of social media in the university premises is the major glitch identified. Faculty and students depended on their Internet connections in their respective houses or outside of the university to coordinate with each other online. Security/privacy, language, content and behavioral issues were other concerns that could be addressed in a social media use guideline.
\end{abstract}

Keywords: Social Media Affordances, Social Media as a Communication Tool, Social Media and Student Services

\section{Introduction}

It is crucial for universities to keep up excellent services to students as their main clientele not only in the academic aspect but also in the administrative/service area. Services rendered by faculty, administrators and various offices (registrar, enrollment provider, accounting, library, sociocultural and sports, scholarship, guidance, student affairs, clinic, zoning and physical infrastructure, colleges and academic departments) do matter to the students' well-being and holistic educational experience in the university thus need constant evaluation by the staff and most of all by the clients themselves. Perpetual communication therefore between service providers in the universities and studentclientele may significantly shape and improve services.
Colleges and departments in general make up the core of the academic organizational structure of universities. It is in the departmental level where students are directly served in their curricular, co-curricular and other organizational concerns (class schedules, student organization activities, consultations, grievances, etc.). In a corporate set-up where clients are greatly valued, most business entities are cognizant of the qualities of their products and services in order to gain more customers and keep them satisfied and loyal.

Academic institutions may be likened to the corporate sector as the former are also expected to build rapport with clients, their students in terms of providing excellent academic and administrative services. A study analyzed the causal relationship between service quality, corporate image, 
satisfaction and loyalty in a sample of students from a vocational training center in Taiwan and one of the findings revealed that both service quality and corporate image have a direct and significant effect on student satisfaction. [1]. It also found that student satisfaction has a direct and significant effect on their loyalty towards the training center. It is therefore presumed that along with the offer of quality education is the continuous improvement of services by the universities to achieve student satisfaction and loyalty.

This current study focuses on the departments' use of social media as a communication tool to engage their students through a platform that affords opportunities for an ubiquitous type of communication hence students are able to give feedback about services, raise legitimate concerns, receive important announcements, participate in department organized online fora and build a strong community that support student-learning and school performance.

Millennials, a term that refers to the generation whose ages range from eighteen (18) to thirty five (35) hence covering ages of those enrolled in universities are known to be generally active users and participants of social media thus communicating with them in this platform may prove to be effective. Social media as a social site has so far has attracted a massive number of users and managed to invite Internet users more quickly than any other online medium in terms of interaction and personalization [2]. It has been reported by the Internet World stats that in 2012 the number of global Internet users amounted to 2, 405, 518, 376 and continues to rise with Facebook being the most popularly used. This trend in communication has indeed taken the center stage in this digital world. Communication in companies, whether private or public and almost all sectors now (education, health, government) are tremendously aided by technology thus merit a scholarly attention in the hope to maximize benefits and address limitations and drawbacks.

The intention of this study is to help academic departments in universities augment the quality of their student services using social media as an innovative communication tool in linking up with their students. The extent of social media utilization and its impact as a tool in managing student services by the selected departments is highlighted in the study. Limitations which includes social media management concerns, under-utilization, misuses and abuses are identified as well in order to explore opportunities for enhancement thus taking full advantage of social media as a communication tool.

Studies concerning the use of social media to support student services in the universities are under explored. This research may be a good addition to the very limited references available.

\subsection{Affordances}

Social Media is known as a set of online tools open for public membership that support idea sharing, creating and editing content, and building relationships through interaction and collaboration [3]. As mentioned earlier, the most popular site is Facebook, which allows users to broadcast messages to a large audience and provide chat options to keep messages private [2]. In this social media platform, communication is brought at a higher echelon in terms of speed, economy and reach. Communicating through social media is the new norm in the $21^{\text {st }}$ century.

Outstanding customer care through social media provides a powerful means for a company to generate competitive advantage [4]. There is a huge advantage of being where the customers are. Therefore if customers are on Facebook, then companies should also be visible on Facebook. Schools adopting such modern strategy in making itself visible to the audiences and taking care of its clients' needs may indeed also potentially place themselves in a competitive advantage over other educational institutions.

Another study investigated strategies and techniques in social media underscoring "engagement mechanism" and reflections on social media experiences by customers [5]. The author purported that social media provides a highly interactive environment that impacts services [5]. Due to interactive communication technologies, organizations have become closer to their customers [6]. In this current study, the use of social media is viewed to potentially offer opportunities of free communication and dynamic interactions among students, administrators, faculty and staff in the academic departments resulting in a closer relationship between students and their departments hence a better learning community.

A study on Social Media in organizations argued that social media have direct bearing on organizational communication processes as they "afford behaviors" that were not made possible before modern technologies were introduced and employed in organizations [7]. The researchers discovered four major affordances that social media provided and these are:

(a) Visibility - making information, knowledge, goals through posts, comments, status of activities, pictures or videos available for the organizational members.

(b) Persistence - accessibility and availability of documented information over time and making them readily retrievable

(c) Editability - recreating, recrafting and editing messages to make them more appropriate and correct.

(d) Association - making connections, establishing social ties with the other members and affiliating with the organization.

Other affordances may surface in the process of further investigation in the context of academic departmental organizations in the university.

\subsection{Limitations and Opportunities for Enhancement}

Literatures have underscored that social media offers immense benefits but is not free from downsides. Innumerable messages broadcasted in this platform could also tend to be overwhelming thus communication breakdown may potentially occur. Lack of regulation and control may encourage misuses and abuses in communication. Other issues could include internal lack of 
capability to manage the platform as disclosed in the study of Mount and Martinez in 2014. Also, in another research, it was found that among the organizations surveyed from Australasia (221) and Europe (596), more than fifty percent lack the following: policies and guidelines, monitoring system of social media content, training and support provided to staff engaged in social media, and social media strategies [8]. This research, which is in the context of academic departments of an educational institution also determines limitations in order to propose a guideline and enhancement techniques in the use of social media to support studentservices.

It has also been pointed out that issues in the use of social media includes spreading of malicious, exaggerated, inaccurate and false information as in the case of a Japanese earthquake and Tsunami in 2011 wherein tweets have been "retweeted" after the victims had be rescued [9]. Issues on privacy and limitations on exploring sensitive topics online were also seen as basis for regulations [9]. Technological limitations were also identified as a constraint, which includes problems in WIFI connections and high administrative cost that were seen as challenges since maintaining social media platforms will require a staff or a team who will manage the activities [9].

Other limitations and concerns in the use of social media can be identified in the current study. Being able to determine these issues will hope to provide useful information that will consequently help leverage use of social media as a communication tool to support student services in universities.

This study is grounded on the Theory of Affordances by James J. Gibson (1979). Affordances means what a thing and its properties can offer, provide, furnish whether good or bad to another. The proponent gives a picture of an environment and what it can offer relative to the animals' needs (water, food, shelter, and other specific needs of a specific type of animal). Gibson coined the word or noun affordances from the verb afford (the term is not found in the dictionary). "The possibilities of the environment and the way of life of the animal go together inseparably. The environment constrains what the animal can do, and the concept of a niche in ecology reflects this fact. Within limits, the human animal can alter the affordances of the environment but is still the creature of his or her situation" [10].

In this study, social media is viewed as the environment having characteristics that offer certain provisions allowing possibilities for humans and organizations to perform certain actions. Limitations are acknowledged and similar to the Theory of Affordance, humans are still perceived to be capable of altering situations.

\section{Methodology}

The seven academic departments as respondents were identified through purposive sampling. These academic departments have been utilizing social media to communicate with their students for administrative reasons. The respondents involved eight (8) administrators who are academic chairs, faculty coordinators and student organization advisers, and one-hundred twenty-three (123) students. Random sampling for the student-respondents of these academic departments was employed on the other hand.

A qualitative approach through open-ended survey was adopted where in answers on affordances and limitations in the use of social media for student services were transcribed and coded. Themes on affordances and limitations were identified from the coded data. The opportunities for innovation were drawn out from the narratives of the respondents and were analyzed consequently.

\section{Results and Discussions}

\subsection{Social Media Used by the Departments in Their Student Services}

The study revealed that the most popular social media platform used by the students, faculty and administrators to communicate with each other in their departments is Facebook. This is expected since the number of Facebook users in the globe has continued to increase from the time this social media platform was introduced in the virtual arena. Among the reasons of its popularity as a social media are wide reach and chat options which allows interactions among the participants. Other online platforms that aid communication in the departments mentioned by some of the respondents are Twitter, Instragram, Yahoo mails and groups, Google mail, Google+, Youtube, Dropbox and Wordpress. Other social media that was found useful for one department to support student services are: Blogger, Wikipedia, Slideshare, Skype and LinkedIn.

It is evident in this study that the available varieties of social media platforms and other forms of online communication are utilized in the student services by the identified departments in the University of San Carlos, Cebu City, Philippines. And since use of social media is restricted in the university, this platform is presumed to be utilized outside of the university premises and beyond office hours.

\subsection{Affordances of Social Media}

\subsubsection{Announcements and Dissemination of Information}

Social Media are found to be highly useful by both faculty/administrators and students for announcements or information dissemination of department and student organization activities - enrollment schedules and concerns such as dissolution of courses, pre-enlistment, co-curricular activities, meetings, general assemblies, seminars, job offerings, student recognition, etc.

The following reveal sample responses:

"Social Media like Facebook is used to inform students with updates from the dept. like enrollment dates; Inform every student with the available schedules, regular class, dissolved subjects and petitions; Update students with different events or activities held by the department." student \#019 
"Social Media assists in Student Enrollment- this is the primary use of social media in our dept. Students have the chance to experience convenience and mobility in saying their enrolment concerns to the dept. w/o the hassle of going to school; Instead students can easily impart their concern in just a click/ moment and all they to do is to wait until the dept. addresses their specific concern; Has easy to announcements and other important info- students can have a clear source of information about a specific announcement through social media and etc." student \#022

Also, a student-respondent finds the social media as a platform for interactions.

"I could easily coordinate with the teachers and my classmates. For the purpose of educational resources- the department shares lecture notes, educational e-materials and etc. Updates - students are easily notified (adjustments, seminars, changes)." - student \#076

Another student-respondent mentioned, "Social media greatly affects my student life. Professors keep in touch with us even outside the classrooms. They may post updates and announcements in a click, and everyone can receive the message." - student \#084

A department Chair also gave similar answers regarding the use of social media in their student services. She narrated that the Social Media are very useful in the following:

1. Announcements during enrolment period which would include opening of new sections, dissolution of subjects. On regular school days, announcements of non-working holidays; no classes due to typhoons, flooding or earthquakes; unscheduled but urgent meetings; etc. academic chair \# 04

2. Inquiries on school, department, class-related concerns. It provides real time conversations and immediate response. - academic chair \#04.

3. Exchange and sharing of Information which includes uploading and downloading of notes, power-point presentations, instructions, forms, references, project studies and the like. - academic chair \#04

4. Conducting surveys for research and thesis related classes, design concepts, and the like." - academic chair \#04

Social media makes the respective departments visible, accessible thus closer to their student-clientele. This is done through posts and various announcements on the platform. The students declared that because of social media, they are updated and made aware of their departments' activities thus there is a perceived "connection" with the organization. Many of the student-respondents find social media a useful platform to assist them in their enrollment and even class concerns hence time and effort of physically going to their departments for some concerns are reduced. Also, reinforcement of class instructions and dissemination of class notes and materials are made possible through the platform. The faculty and department Chairs' answers also concur with the thoughts of the students. They highlighted the affordances of visibility and persistence as also previously mentioned in the study of Treem and Leonardi (2012).

Other uses to maximize social media as a communication tool to support student services:

Online Forum to address issues and complaints

Most of the faculty coordinators and student-respondents think that online discussions or forums on department related concerns, other than enrollment can occur in social media. Online interactions that reveal comments/opinions and helpful suggestions to improve department-support to their students may be facilitated as suggested by many.

Sample responses:

"Online forum is very nice idea. Perhaps, the department can conduct online forums regarding newly-crafted policies that affects the students directly or indirectly. The department may also use social media to address queries from students such as enrollment problem, teacher concerns and the like." student \# 011

"An online forum/discussion can be a good way of improving the student services. There, you will see similar problems being addressed and possible solutions from people who have the same experiences as you." - student \#020

"Social media can be used to organize online forums which can be a venue for sharing ideas, brainstorming and decision-making." - student \#036

"If used responsibly, social media can be used as a venue for informal intellectual discussions that cannot be accommodated in the classroom setting due to limited time." - academic chair \# 02 .

“... serve as a hub for students to discuss matters related to the department or academics, and not just enrolment-related matters." - academic chair \#01.

It is interesting to note that a number of the studentrespondents suggested the possibility of using social media to air out concerns regarding teachers, facilities, etc. and for the departments to be open to their constructive criticisms. Seemingly, the students reiterate in their answers the importance of the academic departments to pay attention to their needs as clients of their respective units and for the departments to consider their opinions and even grievances for the improvement of their respective organizations.

The study reveals a culture of democracy that students expect their academic departments to continuously exercise in their organizations not only during General Assemblies where questions raised by students are addressed by the school and department administrators, faculty and staff in just one sitting but also in other communication platforms such as social media. As social media is able to document these messages (concerns, complaints, opinions, suggestions) from the student-clientele, it will be easier for the departments to retrieve, analyze, filter content, and thoroughly address recurring and relevant issues that need careful attention and strategic action.

Sample responses:

"Be open to the online forum, where students can post anonymously to address their concern about a teacher, or the classroom, everything. Be open to criticism." - student \#022

"It can be used to post comments and suggestions to improve the dept. and point out its flaws (whether it be about teachers or the dept. itself). It can also be maximized through 
online forum in which teachers and the department may be able to post updates." - student \#021.

"Social media could be a good platform where the department could hold online forums among the organization's officers, students and even the faculty. Through this, the gap between individuals could possibly be ironed-out, preventing any issue from creating chaos." student \#054

\subsubsection{Online Tutorials}

Online tutorials have also been brought up by the students in this study. They find social media to be a useful platform to further enhance learning outside of the classroom.

Sample answers:

"By promoting the importance of education through online tutorials and other activities." - student \#049

"In facebook, we could post pictures of our concerns with class or with the school, may be online classes to help students having a hard time catching up with the lessons in class such as: teachers can post videos with current lesson. Students can put questions they have that can be seen by anyone." - student \#088

"Online forum would be nice, specially subject related topics this way when someone ask the instructor some class problem. Everyone can read, view, and reply to it." - student \#091

"Online forums, I believe are very useful for us students because we could teach or tutor one another whenever we encounter problems in class." - student \#092

Delivery of curriculum and instruction as a major part of student-services according to the students will be greatly helped by social media. They find social media a helpful extension and tool to enhance learning experiences that could happen beyond the classroom setting where students and faculty can still interact on certain class topics that need further discussion.

\subsubsection{Avenue for Interactions and Participation in School-Related Discussions}

Social Media is also viewed as an avenue where students can engage themselves in interactions with the other members (students, faculty, administrators) of their departments. Through social media, they are able to actively participate in discussions that have bearing on their being members of their organization by expressing their views, comments and suggestions for the improvement of the department's services.

Sample responses:

"An online forum would be great. Interactive social media greatly improves relationship between students and through this, students can express their views on various topics and issues." - student \#111

"Social media can be used also for discussions and forum regarding an issue/topic that needs suggestions and comments from the student body." - student \#113

Positive impact of social media on the respondents as members of their organization All faculty/administrator and student-respondents claimed that social media has significantly and positively affected them as they go about performing their tasks in the university. Based on the narratives, through social media, enrollment has been greatly aided, communication between departments and their students are perceived to have improved, department-student collaboration is reinforced thus student-services in general is found to be favorable.

Here are some of the common responses of the students:

"As a shiftee from another engineering. I was amazed on how our chairman uses Facebook as a tool to help our enrollment. Gone were the days wherein we all pile up in the department with different problems. It saves the time and effort from both the students and department." - student \#028

"Social media is very effective during enrollment period. It has helped me and the department save in time, effort and even in cist. I no longer had to wait in line in order for my concern to be addressed and in order for me to talk to my teacher since social media allows my questions and concerns to be heard and it has helped me gain info a lot." - student \#029

"It bridges the gap of the dept. and the students through communication." - \#033

"Since almost everyone has social media accounts, announcements and significant information reach to the people/students effectively due to its portability, accessibility." - student \# 034

"Social media actually made my life easier. It provided me easy access to everything." - student \#047

"Teachers have used social media to give soft copies of readings and their power points. Social media helped me save money for without it (and I think I speak for everyone else), It has made easier for us to disseminate information especially since Facebook has a feature that allows you to see the list of people who have "seen" your post. It provides proof and evidence when students play dumb. It also gives us an avenue to reach entire organization since it's expensive to load our mobile phones text messages access to other networks." - student \#051

"Because of the internet accessibility queries, concerns and information dissemination are accurately addressed. Also it saves everyone else's time having internet as a portal where everyone could interact even without physically meeting." student \#054

"I would be spending my allowance on hundreds of photocopies and printings had it not been for course materials which can be accessed through social media." - student \#051

"Time and resources are not wasted if announcements about the class schedules or meetings were changed or any type of announcement/information were addressed through social media. I will not have to waste my time travelling and my money for transportation would also not be wasted. Easy access on files given/uploaded through social media would also help in my studies regarding assignments, projects, etc." - student \#109

"Social media addresses the lack of communication between us students and teacher-student interactions. We can freely discuss about our lessons and school-related topics and 
works without costing us to stay late outside home. It is much easier to send files and important matters that are urgently needed because most of us are active online." - student \#061

"Because of social media, information dissemination is fast especially when one is active in the virtual community. This also gives the convenience between the students and the teachers for them to be able to share files and documents that are needed for class discussions and in such way, since the student is already prompted ahead of time about the class activity, there would be an active and effective class interaction."- student \#108

It is also notable how students appreciate the cost and time saved by social media as they function in their respective organizations.

The following are the responses from the academic chairs and faculty coordinators:

"It has made the resolution of student concerns (related to enrolment) faster and more efficient since there is no need for them to be physically present at the department (except for cases that requires the student to appear personally, e.g. retention cases)." - academic chair \#01

"Information is relayed efficiently (quite fast) thus making students respond to communications from department requesting for student participation in many activities quicker." - academic chair \#03

"Social Media in general is used positively by documenting memories, learning and exploring new things; it can also be used for self-branding and promotion, and is a good way to foster friendship. In the area of student services, social media play an important role in the delivery of such by providing opportunity to communicate, connect and engage. It can serve as contact and check points to reach numerous students to deliver content, to orient, to lobby; to act."academic chair $\# 07$

"Instant interaction, centralized system of information dissemination, connectivity..."- faculty

coordinator \#06

"Faster dissemination of information regarding assignments/class projects/changes of schedule \& other matters." - faculty coordinator \#05

"It has improved our communication and has improved information dissemination." - faculty coordinator \#04

It is evident in this study that social media enable departments to be more visible and accessible to the students thus heightens awareness about co-curricular activities; makes student-life easier; saves effort and time through reduction of offline visits at the departments; lowers expenses for educational materials; improves communication among departments and their students; and allows easy and fast access of information therefore improves studentservices.

On the other hand, limitations and glitches were identified in the use of social media as a communication tool to support student services:

\subsection{Blocking of Social Media Sites in the University}

The university administration has decided to disallow usage of social media as this may interfere very important transactions that are done online (electronic mails, Integrated School Management Information System (ISMIS) functions, online access to the library, etc.). Also, the anticipated overwhelming use of social media for personal purposes is deemed difficult to control and such activities may slow down all the more the Internet service connection hence will potentially affect the facilitation of more vital purposes (administration and academic) to which social media in the university should serve.

Albeit legitimate as a decision, looking into possibilities of investing on internet infrastructure to further expand student services that includes usage of social media for studentdepartment communication and collaborative purposes may still be a worthy effort.

Sample responses:

"Not all students check their Facebook frequently and some students do not have access to Facebook/Wi-Fi especially that USC-WIFI blocked social media. Facebook can't be accessed thru the USC WIFI." - student \#011

"The network infrastructure of the university has made accessing Facebook a limitation (being blocked from access). Thus, resolution of student concerns are not taken cared of immediately." - academic chair \#01

"The department has been using the FB page before Facebook became a restricted site by USC. We can only use the page if we have our own internet connection which goes beyond office hours." - academic chair \#02

"Accessible only to those with internet connection or online and to those who are Facebook users only." academic chair \#04

"First of all, we can't even access the social media that we want to use in our school. So, instead of blocking the sites useful for the teachers/students, internet access should be granted but should be tracked down if the (sites used are) user will be using porn sites and its equivalent." - academic chair \#05

"It is not allowed in the USC Campus so accessibility is limited. Teachers or Admin and students must have their own Internet plan subscription." - academic chair \#04

\subsubsection{Slow Speed and/or Unavailability of Internet Connection for Some Students}

Generally, slow speed of Internet server and expensive Internet connection has been an issue in the Philippines for quite some time thus resulting in a digital divide among the citizens in the country. In a blog titled "The Digital Divide: Challenges and Opportunities in Education”, it is mentioned that the digital divide in the Philippines is still of a wide range, with a lot of areas still having limited access to technology. One cannot therefore expect that everyone, or all university students in this matter have access to the Internet. This may therefore require students to invest on portable wifi and other types of Internet connections for them to be updated, informed and be with other members of their departments online.

"Internet connection is also not readily available all the 
time since some only have limited access. Mobile data or other resources are still needed and that includes a good signal for any network." -student \#109

"Not all students check their social media accounts 24/7 and if you don't regularly check, you wont know about announcements. There are also students w/ limited/no internet connection. It would be difficult for them." - student \#110

"The internet connection may cause the late arrival of some messages or posts of students in Facebook. Facebook's server may as well serve as a problem." -academic chair \#01

\subsubsection{Unavailability of Person/s from the Departments That Could Address Concerns 24/7}

This is expected since it is not part of the job descriptions of the department heads, coordinators, staff and studentadvisers to go online to respond to messages sent. This is also the reason why not all departments facilitate interactions with students online since this could mean putting extra effort by working beyond their duty hours in their offices. As to those departments who avail of the affordances of social media to support student- services, it is presumed that they have devised strategies such as division of labor among coordinators, student-advisers, student-organization officers and have become selective in responding to highly important messages which need immediate attention.

Also, one cannot expect all members of the organization to be online all the time to check out what is going on and respond to messages that need attention since they are also expected to be engaged in other activities offline.

Sample responses:

"Internet connection is limited since it's not always that I am connected. Fewer interactions with the administrator in that social media. You are not entertained as soon as possible for the some reason as the first or he/she is busy doing something else. Miscommunication can happen as well. Repetitive questions can occur that can result to some unassured queries." - student \#020

"Not all student concerns are addressed in social media for student services. Ex. In environment, there are certain concerns that the dept. will cater, other than those not emphasized in FB photos (for specific concerns) will not be entertained."-student \#022

"Limitation is the time since the some of the faculty are not always available. The internet areas is also major problem since not every corner of the school has Wi-Fi and seldom, when there is an internet, the connection is very low. At home, I don't have problem with the internet connection but when rainy season, I suffer with it." - student \#025

\subsubsection{Lack of Sincerity and Clarity in the Messages Due to the Absence of Non-verbal Cues}

Clarity in communication may become an issue since online communication is bereft of non-verbal gestures, cues which greatly support communication hence the need for discussing highly important matters and complicated issues offline rather than online. In cases where communication becomes confusing and unsuccessful due to the limitations of computer-mediated-communication, it is imperative for interlocutors to resort to Face-to-Face ( $F$ to $F$ ) type of interactions.

Sample responses:

"Social media means investments in internet services that is of good quality. Also, posts in social media have the tendency to get deflect- meaning many people may alter information." - student \#014

"Some problems/comments regarding enrollment are sometimes ignored; Difficult for students to explain or clarify complicated problems; there could be conflict due to misunderstanding." - student \#021

"A lot of confusions may arise; If the teacher does not diligently check notifications, concerns will not be entertained and will be put on hold..." - student \#029

"Explanations through words may not be enough."student \#029

"We can't really see the emotion on the face on the things we are addressing to."- student \#040

"Sometimes, there might be occurrences of miscommunication or misinterpretation as it is done behind a screen so some intended meanings might not be properly addressed." - student \#045

"There are some things that can't be thoroughly and fully explained through the chat box that formality of personally communicating the person is needed. Not everyone will be online all the time, and not everyone will reply right away due to problems which may be technical or non-technical." student \#063

"There are instances that information is not correctly interpreted." - student \#044

\subsubsection{Tendency of Participants to Resort to Cyber Bullying}

According to a study titled Ongoing and Online: Children and Youth's Perception of Cyberbullying, "While most online interactions are neutral or positive, the Internet provides a new means through which children and youth are bullied" [11]. Cyberbullying is a known phenomenon in the Internet. Due to the anonymity afforded online, some participants find this liberating and abuse this freedom by verbally attacking other individuals.

Sample answers:

"Students bluntly criticize other students." - student \#023

"Limitations in giving complaints or problems, because such thing might result to cyberbullying." - student \#026

"Foul or unpleasant words may be displayed." - student \#029

"Cyber bullying, it is just in a virtual world and not in a real world and so there is a huge difference between meeting/talking him/her in person and talking/chatting him/her through social medias. Since you cannot directly receive a reply for all of your comments, queries, suggestions and etc. because it depends when will the person be online." - student \#075

\subsubsection{Security/Privacy, Language, Content and Behavioral Issues}

The respondents in their answers brought up issues on 
hacking and other security concerns. Likewise, potential corruption of files was also mentioned. This is another common concern that could transpire in the virtual community. In an article titled "Click and connect: Young Australian's use of online social media", it is stated that "Research in the European Union has identified three key areas of concern in relation to cyber-safety risks for children and young people. These are:

[1] content risks: including illegal exposure to illegal content, exposure to harmful content, encountering sexual/violent/racist/hate material, misinformation, problematic user-generated content, challenging content (or example, suicide, anorexia and drugs)

[2] 'contact risks': including contact with strangers and cyberbullying and

[3] 'privacy' risks: including giving out personal information, invasion of privacy and hacking" (p. 14)"

Also, respondents declared that irrelevant postings can occur hence giving inappropriate or wrong information veering away from the real topic at hand. The number of posts can also be overwhelming resulting to information overload.

Sample responses:

"Can be hacked/tampered with." - faculty coordinator \#06

"It can be hacked, it could malfunction and sometimes information dissemination might possibly be unverified." student \#054

"The problems and challenges in the use of social media for student services are: Power outage, unavailability of hardware and gadgets, security issues (hacking/tampering, etc.)." - academic chair \#07

"The limitations would include security and privacy issues, no central source of information brought about by numerous social media options." - academic chair \#07

"Another problem is the students' lack of ability to follow up and get feedback about their concerns. And the attitude or manner of students in using social media is also an issue. Students seem to forget that they are addressing an office, not a peer. Then there's the problem on slow internet connectivity." - academic chair \#02 -Chair

"Due to multiple postings, other information may not be seen/ will be buried in the feed. Only those w/ numerous interactions can be readily seen." - student \#074

"Unrelevant postings or unnecessary posts." -student \#069

"Sometimes it is not from trusted sources." - student \#097

"Distracting too many info on one's newsfeed announcement get buried in the timeline." - faculty coordinator \#06

"Sometimes it is made used by students to post information that are not relevant or useful." - academic chair \#03

"... the use/access of sexually explicit sites and big files that are downloaded from torrent sites." - faculty coordinator \#05
"One limitation of social media is that some information disclosed might not be reliable, or it is outdated..." student \#079

“Asking too many questions from A-Z"- student \#041

\subsection{How These Limitations and Glitches Can Be Addressed}

\subsubsection{Social Media Be Made Accessible in the University Premises and Invest on a Reliable Internet Provider}

Most of the suggestions center around having access to social media in the university and for the university to invest on a reliable Internet provider or a stronger bandwidth.

Sample answers:

"By providing a special access for administrative positions (chairs and deans for examples) to some sites that prove useful in serving our clients." - academic chair \#01

"Remove restrictions from social media." - academic chair \#02

"The University can create an official and particular account whereby students can access information, follow announcements, schedules and warnings; and finally connect with classmates and teachers." -academic chair \#07

"By providing a dedicated server for these kinds of connections, these glitches may be addressed." - academic chair \#01

"These problems and challenges can be addressed by: Provision of generators and availability of power banks, provision of kiosk or location with computer units to access social media sites, provision of official sources or account for students to access." - academic chair \#07

"There has to be an official account." - faculty coordinator \#07

"Allow facebook access in the campus." -academic chair \#04 -

"It can be addressed by having a University wide WIFI so that everybody can have a chance to read the announcements."- student \#012

"These limitations can be addressed through communication those people who can make all of these things possible especially in the case of limited connection of internet. "Telecommunication Companies". "There should be an improvement to be done by them."-student \#016

"Applying for a fast internet connection at home or maybe the University has to provide accessible Wi-Fi around the campus.; Hire another secretary for such or maybe let the instructors be provided with internet connection as well."student \#031

"I think it can be addressed if students individually would be given a way to connect the web easily. It is either put by stations within the school were students can easily get info from social media." - student \#106

\subsubsection{Creating a Team Who Could Manage Social Media}

Respondents are suggesting that there should be people or a team who will manage the social media. They maybe composed of the academic chair, coordinators, secretary, faculty-advisers and student representatives who could regularly monitor, filter and attend to important 
administrative concerns of the department.

Sample responses:

"These limitations can be addressed if someone will be assigned to handle that particular task." - student \#022

"Other Faculty members should help the chairman in terms of announcements." - student \#028

"The department could create a team of five people from the students and possibly an adviser from the faculty to manage the social medium chosen by the dept. This will also help the department sort out the issues raised by the students to be addressed quickly and directly by the dept."- student \#054

"By putting someone to manage the page and answers the questions of each questions." - student \#056

\subsubsection{A Combination of Face-to-Face and Online Interactions Be Employed in the Communications}

A combination of face-to-face and online communication surfaced as a suggestion. The student-respondents think that it is still necessary to have department general assemblies and other face-to-face encounters of the organizational members. Also, traditional bulletin boards for posting of announcements are still considered useful.

Sample answers:

"I think the department should have an open forum and limitations about social media usage should be discussed. It should be emphasized that the students though so engrossed with social media should be taught or informed inside the classroom because sometimes information and perceived falsely." - student \#048

"Random information dissemination should not be limited only on social media." - student \#017

"Face-to-face updates of the department." - student \#052

"Posting in bulletin boards, making Facebook just the MAJOR but not the SOLE avenue for information dissemination. It's hard to address the multiple accounts users since these are personal accounts we have no control over."- student \#053

"We should not be very much dependent to the internet."student \#064

\subsubsection{Sanctions Be Given to Those Who Engage in Cyber Bullying}

"Reports on foul/unpleasant words should be addressedbanning of users can be done..."- student \#029

"Everyone should be given freedom to access the sites, however (the users should be reprimanded) a tracking system should used to notify or apprehend the violations. Continuous violation be sanctioned accordingly." - faculty coordinator \#06

"Block the users who do it." - student \#070

"Filter these posts to prevent users from viewing them or just ban these posts." - student \#069

\subsubsection{Security/Privacy, Language, Content and Behavioral Issues Should Be Managed, Monitored and Controlled}

"Create private groups with limited access, limit sharing capabilities among members of a group/page." - faculty coordinator \#05

"They should create a website exclusive for the students in a certain department wherein they are already signed up using ID numbers."- faculty coordinator \#003

"Use of images to stand out..." -faculty coordinator \#05

"I strongly believed that a lecture on the responsible use of social media would help students addressed these problems." - academic chair \#02

"Proper orientation on the use of the social media..."academic chair \#03

"Block the sexually explicit sites."- faculty coordinator \#06

"Things posted must not go beyond certain school matters."- student \#047

"Should be limited to educational purposes only or schoolrelated stuff." - student \#049

"For me as long as there's a proper orientation between the department and the students on how they'll communicate and now announcements will be posted, the problem could be lessen."- student \#010

"Strict monitoring of posted messages." - student \#090

"Be more responsible for your actions. Think twice before you click." - student \#075

\subsubsection{The Need of a Social Media Use Policy and What It Should Include}

When asked whether a social media policy is necessary, an overwhelming approval of having one is evident in the answers.

Responses from the Academic Chairs \& Faculty Coordinators:

"Yes, there should be. Especially on who can use the social media and who has access." -academic chair \#01

"Yes I believe there must be guidelines like:

1) Who will be the administrator?

2) Who can posts?

3) What posts or announcements should be shared online?

4) How should students behave in terms of language usage and tact?" - academic chair \#02

"Even if it is not made available at the university, it is worthwhile to present some guidelines to students (and faculty) on the use of social media - Tips on what and when to post. If officially used as part of student services then it is necessary. As a means to regulate its use, the consequences ("penalty", in lack of a better word) that a student will face in case of misuse." - academic chair \#03

"Online bullying/memes, spreading of malicious/false information, plagiarism." - faculty coordinator \#05

"Privacy Issues, quality of posts/ censorship." - faculty coordinator \#06

"Ethics and Etiquettes, piracy concerns, plagiarism, censorship, false information, online bullying, offense and sanctions." - academic chair \#07

"Avoid of using foul language." - faculty coordinator \#08 - faculty coordinator

Responses from the students:

"Yes, No foul language, information should be carefully 
reviewed before posting." - student \#003

"Yes, guidelines which include procedure in filing forms. Such as when filing a complaint form, the department may site certain provisions or steps on how it can be done." student \#011

"Yes, proper sharing of information, proper addressing of concerns and social media ethics." - student \#012

"Yes, so that the use of social media for student services will be more convenient o students as different concerns will be addressed and entertained.; There should be no irrelevant posts to the social media forums whoever will disobey can no longer avail/ experience this student services." - student \#022

"Yes. Like how to send private messages to specific teacher if you have important concerns to them because there are some messages that need not to be known/seen/read by other people." - student \#027

"Yes, there should be a guidelines. Individuals should be careful with their actions. Only post relevant things." student \#046

"Yes. There are some parts of the internet that are sensitive and are not meant to be seen by students. For example these are pages that shows explicit materials on some pages should be taken down. Profiles should be used for school purposes." - student \#050

"Yes, I strongly agree there should be a guideline for social media utilization simply because social media may be used as an act or wall that protects people behind the digital screen when they can't even show a face in the real world. Examples: In posts concerning official announcements or information, there must be no foul words or language found in the post or comment box." - student \#053

"Yes. What concerns/issues will be entertained by the page? To share a post/information, the monitoring team must approve it first before it gets published in the page. There must be sanctions to students who make rude comments, irrelevant concerns and non-sense issues." - student \#054

\section{Summary of Findings}

The respondents claimed that the use of social media provided them strengthened connection with the members of their departments. Enrollment activities are supported, as students do not need to physically congregate in their departments to discuss concerns. Announcements and dissemination of information are also made visible and accessible online. Other social media affordances include opportunities to hold online fora and continuous interactions to address issues and complaints.

Blocking of social media sites in the university premises was the major glitch identified. Other respondents also mentioned slow speed and/or unavailability of Internet connection for some students in their respective houses. Administrators, faculty and students deem it important to assign specific people or team to manage and attend to the social media platform to maximize its function and affordances. It was notable that the respondents underscored the need for face-to-face interactions and not resort to over reliance on social media in their communication activities as the latter mode of communication could have the tendency to send unclear messages due to the absence of non-verbal cues. The respondents were in favor of crafting a guideline for social media use to address issues on language abuse and other online behavioral issues, content, and security/privacy concerns.

\section{Conclusions}

The use of social media as a communication tool is a commendable modern strategy to improve academic departments' services to its students since this affords continuous connections among organizational members. Based on the experiences of the departments who employ this method, a number of department coordination activities are perceived to be highly assisted and this has made a positive impact on department-student communications in general. However, it is underscored that this approach should still be combined with face-to-face interactions especially on occasions when interactions need to be more elaborate thus holding of general assemblies and periodic meetings are still regarded important. Along with the use of social media are glitches and limitations related to security/privacy, content, language and online behavioral issues. These may be addressed by creating guidelines or policies in aid of regulation.

Universities may explore possibilities of allowing use of social media to improve student-services, and investing on the necessary technological infrastructure and personnel who will maintain such media. Also, forming teams composed of the Chair, coordinators, student-advisers and student organization representatives themselves is crucial since they are the ones responsible for the facilitation, monitoring, and maintenance of their platforms. In this connection, incentivizing team members for their extra effort is also seen imperative.

\section{Acknowledgments}

The researcher would like to thank the University of San Carlos of Cebu City Philippines for its continued support to its university faculty-researchers. Also, the researcher wishes to thank the academic departments who participated in this study and shared their valuable insights on the use of social media as a communication tool to help support facilitation of university-student services.

\section{References}

[1] Kuo, Y. K. \& Ye, K. D. (2009). The Causal Relationship Between Service Quality, Corporate Image and Adults' Learning Satisfaction and Loyalty: A Study of Professional Training Programmes in a Taiwanese Vocational Institute. Total Quality Management \& Business Excellence, 20 (7), 749-72.

[2] Zolkepli, Izzal Asnira and Yusniza Kamarulzaman (2015). Social media adoption: The role of media needs and innovation characteristics. Computers in Human Behavior. Volume 43, pages 189-209. 
[3] Mount, Matthew and Marian Garcia Martinez (2014). Social Media: A Tool for Open Innovation. California Management Review. Volume 56, No. 4, pages 124- 143.

[4] Newman, Bruce (2014). Service in social media can boost a company's reputation. Westchester Country Business Journal. Volume 50, Issue 27, p. 26.

[5] Nikolić, Predrag K. (2014). Engagement Factors in Social Media Experience. Singidunum Journal of Applied Sciences. DOI: 10.15308. pages 209-212. SInteZa.

[6] Talpau, Alexandra (2014). Social Media- A New Way of Communication. Bulletin of Transilvania University of Brasov Series V: Economic Sciences. Volume 7 (56). No. 2, pages 4552.

[7] Treem, J. W. \& Leonardi, P. M. (2012). Social Media Use in Organizations: Exploring the Affordances of Visibility, Editability, Persistence, and Association. Communication Yearbook, 36, 143-189.
[8] Macnamara, J., \& Zerfass, A. (2012). Social media communication in organizations: The challenges of balancing openness, strategy and management. International Journal of Strategic Communication, 6 (4), 287-308. DOI: 10.1080/1553118 X.2012.711402.

[9] Lindsay, Bruce (2011). Social Media and Disasters: Current Uses, Future Options, and Policy Considerations. Retrieved, April 13, 2016 from https://www/fas/org/sgp/crs/homesec/ R41987.pdf.

[10] Gibson, James (n. d.). The Theory of Affordances from The Ecological Approach to Visual Perception. Retrieved, April 16, 2016 from cs.brown.edu/courses/cs/137/readings/GibsonAFF.pdf.

[11] Mishna, Faye, Michael Saini and Steven Solomon (2009). Ongoing and Online: Children and Youth's Perception of Cyberbullying. Children and Youth Services Review. Elsevier Ltd. pp. 1222-1228. 